\title{
Off-pump coronary bypass surgery: risk of ischemic brain lesions in patients with atheromatous thoracic aorta
}

\author{
[Le pontage aortocoronarien à cour battant: risque de lésions cérébrales \\ ischémiques en présence d'une aorte thoracique athéromateuse]
}

George Djaiani MD FRCA, ${ }^{*}$ Ludwik Fedorko MD PhD, ${ }^{*}$ Robert J. Cusimano MD, $†$ David Mikulis MD, $\ddagger$

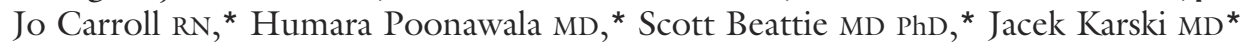

Purpose: The purpose of this study was to determine if there is an association between the proximal thoracic aortic (ascending aorta and aortic arch) atheroma and ischemic brain lesions on diffusion-weighted magnetic resonance imaging (DW-MRI) after on-pump (ONCAB) and off-pump (OPCAB) coronary artery bypass surgery.

Methods: Patients who underwent ONCAB surgery $(n=13)$ and who had aortic atheroma $>2 \mathrm{~mm}$ were compared to a risk-adjusted prospective cohort of patients $(n=13)$ undergoing OPCAB surgery. Transesophageal echocardiography and epiaortic scanning were performed to assess the proximal thoracic aorta. Patients were evaluated for new ischemic brain lesions utilizing DW-MRI three to seven days after surgery. The NEECHAM confusion scale was used to evaluate patient consciousness.

Results: The groups were comparable with respect to demographic data, and prevalence of preoperative risk factors. The extent and severity of aortic atheroma was similar in the two groups. The average maximum height of atheroma was $5.0 \pm$ $2.0 \mathrm{~mm}$ in the OPCAB and $4.8 \pm 1.9$ in the ONCAB groups, respectively. The prevalence of new ischemic brain lesions on DW-MRI was $0 \%$ in the OPCAB group and $61 \%$ in the ONCAB group $(P=0.00 \mathrm{I})$. Patients in the OPCAB group were less confused during the first two postoperative days.

Conclusion: Patients with aortic atheroma $>2 \mathrm{~mm}$ may have a lower risk of new ischemic brain lesions as identified by DW$M R I$ after OPCAB surgery. Patient stratification based upon aortic atheroma burden should be addressed in future trials designed to tailor treatment strategies to improve short- and long-term neurological outcomes in patients undergoing cardiac surgery.
Objectif: Déterminer s'il y a une association entre l'athérome de l'aorte thoracique proximale (aorte ascendante et crosse de l'aorte) et les lésions cérébrales ischémiques à l'examen d'imagerie par résonance magnétique pondérée par diffusion (IRM-PD) à la suite du pontage aortocoronarien avec circulation extracorporelle (PACCE) et un PAC à cœur battant (PACCB).

Méthode : Des patients subissant un PACCE $(n=13)$ et ayant de l'athérome aortique $>2 \mathrm{~mm}$ ont été comparés à une cohorte prospective de patients à risque ajusté $(n=13)$ subissant un PACCB. L'échocardiographie transœsophagienne et le balayage épiaortique ont permis d'évaluer l'aorte thoracique proximale. La présence de nouvelles lésions cérébrales ischémiques a été vérifiée avec I'IRMPD trois à sept jours après l'opération. La conscience des patients $a$ été évaluée par l'échelle de confusion NEECHAM.

Résultats: Les données démographiques et à la prévalence de facteurs de risque préopératoires intergroupes étaient comparables. L'étendue et la sévérité de l'athérome aortique étaient aussi similaires. La hauteur maximale moyenne de l'athérome était de 5,0 $\pm 2,0 \mathrm{~mm}$ pour le groupe de PACCB et de 4,8 $\pm 1,9$ pour le groupe de PACCE. La prévalence de nouvelles lésions cérébrales ischémiques à l'IRM-PD était de $0 \%$ avec PACCB et de $61 \%$ avec le PACCE $(P=0,00 I)$. Les patients de PACCB étaient moins confus pendant les deux premiers jours postopératoires.

Conclusion: Les patients avec athérome aortique $>2 \mathrm{~mm}$ peuvent présenter un risque plus faible de lésions cérébrales ischémiques comme l'a montré l'IRM-PD après le PACCB. La stratification des patients selon le degré d'athérome aortique devrait être étudiée ultérieurement pour adapter les traitements visant à améliorer les résultats à court et à long terme chez les patients qui subissent une intervention chirurgicale cardiaque.

From the Department of Anesthesia and Pain Medicine, ${ }^{*}$ the Division of Cardiac Surgery, $\uparrow$ and Neuroradiology, $\ddagger$ Toronto General Hospital, University Health Network, University of Toronto, Toronto, Ontario, Canada.

Address correspondence to: Dr. George Djaiani, Department of Anesthesia and Pain Medicine, Eaton North 3-410, Toronto General

Hospital, 200 Elizabeth Street, Toronto, Ontario M5G 2C4, Canada. Phone: 416-340-4800, ext.6205; Fax: 416-340-3698;

E-mail: george.djaiani@uhn.on.ca

Accepted for publication January 10, 2006.

Revision accepted March 2, 2006.

Competing interests: None declared. 
A considerable number of elderly patients undergoing cardiac surgery develop neurological complications ranging from subtle Cognitive changes to more evident postoperative confusion, delirium, and less commonly, clinically apparent stroke. ${ }^{1-3}$ Atherosclerosis of the ascending aorta and the aortic arch is one of the most important risk factors for perioperative stroke..$^{4-8}$

Recently, we reported that patients with atheromatous disease of the proximal thoracic aorta (ascending aorta and aortic arch) undergoing coronary artery bypass $(\mathrm{CAB})$ surgery with cardiopulmonary bypass (CPB) were exposed to a high risk of ischemic brain injury as identified by diffusion-weighted magnetic resonance imaging (DW-MRI). These patients had a threefold increase in cerebral embolic load during $\mathrm{CPB}$, and a change in postoperative mental status when compared to patients with a normal aorta. ${ }^{9}$

The purpose of this study was to determine whether or not there is an association between proximal thoracic aortic atheroma and ischemic brain lesions on DW-MRI after on-pump (ONCAB) compared to off-pump (OPCAB) CAB surgery.

\section{Methods}

Study population

After Institutional Review Board approval, informed consent was obtained from patients over $60 \mathrm{yr}$ of age scheduled for elective coronary revascularization surgery. Patients with known contraindications to MRI, history of stroke, atrial fibrillation, and symptomatic carotid artery disease were excluded. Patients with a normal proximal thoracic aorta, or severe, diffuse calcification of the ascending aorta ('porcelain aorta'), or mobile plaques determined during intraoperative echocardiography, and those who required conversion from $\mathrm{OPCAB}$ to $\mathrm{ONCAB}$ were also excluded from the study.

Patients with aortic atheroma $>2 \mathrm{~mm}$ who underwent ONCAB surgery $(n=13)^{9}$ were compared to a risk-adjusted prospective cohort of patients $(n=13)$ undergoing OPCAB surgery. All patients were evaluated for new ischemic brain lesions utilizing DW-MRI three to seven days after surgery.

\section{Echocardiographic assessment}

All patients underwent transesophageal echocardiography (TEE) and epiaortic scanning of the proximal thoracic aorta. Echocardiographic data was acquired using a Hewlett-Packard Sonos $5500^{\mathrm{TM}}$ (Agilent Technologies, Andover, MA, USA) ultrasound system equipped with multiplane 4-7 $\mathrm{MHz}$ transesophageal and 6-15 MHz epiaortic probes. The TEE examina- tion was performed after induction of anesthesia. After median sternotomy, the epiaortic probe was used by the surgeon to scan the ascending aorta from the aortic valve to the proximal arch in transverse and longitudinal planes.

Grading of the aorta was determined according to intimal aortic thickness: $\leq 2 \mathrm{~mm}$ (grade 0$) ; 2-4$ $\mathrm{mm}$ (grade 1 ); > $4 \mathrm{~mm}$ (grade 2 ); and presence of mobile atheroma (grade 3). ${ }^{5,10}$ The same weighting criteria were applied to the presence of atheroma in the ascending aorta, and the aortic arch. Only patients with grade 1 or grade 2 atheroma were included in this study.

\section{Management strategies}

Anesthetic techniques were similar between the two groups. Premedication consisted of lorazepam 2-4 mg $s l$ one-hour before surgery. Anesthesia was induced with fentanyl 10-15 $\mu \mathrm{g} \cdot \mathrm{kg}^{-1}$ iv and propofol $\mathrm{l}-1.5$ $\mathrm{mg} \cdot \mathrm{kg}^{-1}$ iv Pancuronium $0.1 \mathrm{mg} \cdot \mathrm{kg}^{-1}$ iv was administered to facilitate tracheal intubation. Anesthesia was maintained with propofol infusion at $\mathrm{l}-4 \mathrm{mg} \cdot \mathrm{kg}^{-1} \cdot \mathrm{hr}^{-1}$ and isoflurane. Only patients in the ONCAB group received tranexamic acid $50 \mathrm{mg} \cdot \mathrm{kg}^{-1}$ iv prior to sternotomy. Heparin $2-3 \mathrm{mg} \cdot \mathrm{kg}^{-1}$ iv was used in the OPCAB group to maintain activated clotting time $(\mathrm{ACT})>300 \mathrm{sec}$, and $3-4 \mathrm{mg} \cdot \mathrm{kg}^{-1} i v$ in the ONCAB group to maintain ACT $>450 \mathrm{sec}$.

All patients underwent median sternotomy. Management of $\mathrm{CPB}$ included systemic temperature drift to $33-34^{\circ} \mathrm{C}$, alpha-stat $\mathrm{pH}$ management, mean perfusion pressure between 50 and $70 \mathrm{mmHg}$, nonpulsatile pump flow rates of $2.0-2.4 \mathrm{~L} \cdot \mathrm{min}^{-1} \cdot \mathrm{m}^{-2}$, and hematocrit $>20 \%$. A 32- $\mu \mathrm{m}$ filter (Avecor Affinity, Minneapolis, MN, USA) was used in the arterial perfusion line. The aortic cannulation, cross-clamp application, and placement of proximal grafts were performed under a single cross-clamp application in the disease free area of the ascending aorta (grade 0 aorta, confirmed by epiaortic scanning). Prior to separation from $\mathrm{CPB}$, patients were re-warmed to nasopharyngeal temperature $36-37^{\circ} \mathrm{C}$. During rewarming the maximal inflow temperature was limited to $37^{\circ} \mathrm{C}$. Protamine $1 \mathrm{mg} \cdot 100 \mathrm{U}^{-1}$ of heparin was used to fully reverse heparin in both groups.

In the OPCAB group, after performing epiaortic scanning, a partial aortic clamp was used in the atheroma free area of the ascending aorta (grade 0 aorta) to assist with construction of proximal coronary anastomoses. The mean arterial blood pressure was maintained above $60 \mathrm{mmHg}$.

After surgery, all patients were transferred to the intensive care unit for postoperative ventilation. 
Sedation was achieved with propofol infusion $0.5-4$ $\mathrm{mg} \cdot \mathrm{kg}^{-1} \cdot \mathrm{hr}^{-1}$ and morphine boluses. Patients were extubated according to the following criteria: patient responsive and cooperative, $\mathrm{SaO}_{2} \geq 94 \%$ with $\mathrm{FIO}_{2} \leq$ $60 \%$, complete reversal of neuromuscular blockade, $\mathrm{PaCO}_{2} 35-55 \mathrm{mmHg}$, stable hemodynamics, absence of uncontrolled arrhythmia, and nasopharyngeal temperature $>36^{\circ} \mathrm{C}$.

\section{Magnetic resonance imaging assessment}

Patients were evaluated for new ischemic brain lesions utilizing DW-MRI three to seven days after surgery. The MRI protocol consisted of sagittal Tl, axial diffusion $(5 \mathrm{~mm}$ thick no inter-slice gap whole brain diffusion images), axial echo-planar imaging gradient echo, echo-planar imaging fluid-attenuated inversion recovery, and phase contrast magnetic resonance angiography sequences. Voxel size for the diffusion sequences was $1.6 \times 1.6 \times 5 \mathrm{~mm}$.

The MRI data were analyzed for overall incidence of new ischemic lesions which were visible as high signal areas on diffusion-weighted image and low signal areas on the apparent diffusion coefficient (ADC) maps. New ischemic lesions were identified as regions of signal hyperintensity on DW imaging (three orthogonal gradient directions, $b=1000 \mathrm{sec} \cdot \mathrm{mm}^{2}$ ) and signal hypointensity on the apparent diffusion coefficient maps. Diffusion-weighted and ADC images were analyzed for the number, location, and size of each lesion. Magnetic resonance imaging results were reviewed by a single neuro-radiologist who was blinded to patient group assignment.

\section{Assessment of consciousness}

Patient consciousness assessment was conducted utilizing the NEECHAM confusion scale ${ }^{11}$ at six discrete time periods: preoperatively (baseline), and postoperatively daily (days one to five). The NEECHAM confusion scale was divided into three subscales pertinent to patient cognitive function, behaviour, and physiologic/autonomic stability. Total score indicated the different degrees of confusion and was weighted as follows: $0-19$, moderate to severe confusion; 20-24, mild or early development of confusion; 25-26, 'not confused' but at high risk; 27-30, normal function.

\section{Study design and statistical analysis}

One of the purposes of this pilot study was to address sample size requirements for a large randomized controlled trial comparing $\mathrm{ONCAB}$ and $\mathrm{OPCAB}$ techniques in patients with atheromatous aorta. The design of the current study was to compare 13 ONCAB patients who had documented aortic ath-
TABLE I Description of patient demographic data and surgical characteristics

\begin{tabular}{|c|c|c|}
\hline & $\begin{array}{l}\text { OPCAB group } \\
(n=13)\end{array}$ & $\begin{array}{l}\text { ONCAB group } \\
(n=13)\end{array}$ \\
\hline \multicolumn{3}{|l|}{ Demographics } \\
\hline Age $(\mathrm{yr})$ & $70.1 \pm 6.7$ & $70.3 \pm 6.4$ \\
\hline Male/female $(n)$ & $9 / 4$ & $10 / 3$ \\
\hline Height $(\mathrm{cm})$ & $170 \pm 10$ & $168 \pm 12$ \\
\hline Weight (kg) & $87 \pm 24$ & $85 \pm 21$ \\
\hline \multicolumn{3}{|l|}{ Co-morbidities } \\
\hline Myocardial infarction $(n)$ & 5 & 5 \\
\hline Congestive heart failure $(n)$ & 3 & 2 \\
\hline $\begin{array}{l}\text { Left ventricular ejection } \\
\text { fraction }<40 \%(n)\end{array}$ & 2 & 1 \\
\hline Hypertension $(n)$ & 8 & 7 \\
\hline Peripheral vascular disease $(n)$ & 1 & 1 \\
\hline Obstructive pulmonary disease $(n)$ & 1 & 1 \\
\hline Diabetes mellitus $(n)$ & 4 & 5 \\
\hline \multicolumn{3}{|l|}{ Preoperative medication } \\
\hline ACE inhibitors $(n)$ & 6 & 6 \\
\hline$\beta$-blockers $(n)$ & 8 & 9 \\
\hline Calcium channel blockers $(n)$ & 6 & 5 \\
\hline Nitrates $(n)$ & 9 & 8 \\
\hline Aspirin $(n)$ & 10 & 11 \\
\hline Lipid lowering drugs $(n)$ & 11 & 10 \\
\hline \multicolumn{3}{|l|}{ Coronary artery bypass surgery } \\
\hline Distal anastomoses $(n)$ & $3.6 \pm 0.7$ & $3.6 \pm 0.6$ \\
\hline $\begin{array}{l}\text { Duration of cardiopulmonary } \\
\text { bypass (min) }\end{array}$ & NA & $78 \pm 24$ \\
\hline Duration surgery $(\mathrm{min})$ & $155 \pm 34$ & $168 \pm 40$ \\
\hline
\end{tabular}

Data presented as mean $\mathrm{SD}$, or $n=$ number of patients. $\mathrm{OPCAB}=$ off-pump coronary artery bypass; ONCAB = on-pump coronary artery bypass; $\mathrm{ACE}=$ angiotensin-converting enzymes; $\mathrm{NA}=$ not applicable.

eroma $>2 \mathrm{~mm}$ to a risk-adjusted prospective cohort of 13 patients undergoing $\mathrm{OPCAB}$ surgery. We hypothesized that OPCAB surgery would be associated with lower risk of new DW-MRI lesions.

Comparability of both groups was tested with the use of Chi-square statistics or Fisher's exact t test on qualitative variables as appropriate and the test and ANOVA on quantitative variables. The association between atheroma and MRI brain infarcts was assessed using a $2 \times 2$ contingency table. One-way ANOVA was used to compare the NEECHAM scores. A $P$ value $<0.05$ was considered significant. Statistical analysis was conducted with the MINITAB computer software (Minitab Inc., University of Wales, Cardiff, UK).

\section{Results}

Demographic data and surgical characteristics

Both groups were similar with respect to demographic data, prevalence of preoperative risk factors, and surgical characteristics (Table I). 
TABLE II Location and severity of atheroma in ascending aorta and aortic arch

\begin{tabular}{|c|c|c|c|c|}
\hline \multirow[t]{2}{*}{$\begin{array}{l}\text { Atheroma } \\
\text { grade }\end{array}$} & \multicolumn{2}{|c|}{$\begin{array}{c}\text { OPCAB group } \\
(n=13)\end{array}$} & \multicolumn{2}{|c|}{$\begin{array}{c}\text { ONCAB group } \\
(n=13)\end{array}$} \\
\hline & $\begin{array}{l}\text { Ascending } \\
\text { aorta }\end{array}$ & $\begin{array}{l}\text { Aortic } \\
\text { arch }\end{array}$ & $\begin{array}{l}\text { Ascending } \\
\text { aorta }\end{array}$ & $\begin{array}{l}\text { Aortic } \\
\text { arch }\end{array}$ \\
\hline Grade 1 & $n=2$ & $n=5$ & $n=3$ & $n=4$ \\
\hline Grade 2 & $n=4$ & $n=6$ & $n=2$ & $n=6$ \\
\hline
\end{tabular}

Grade $\mathrm{l}=$ maximum height of atheroma $>2-4 \mathrm{~mm} \leq$; grade $2=$ maximum height of atheroma $>4 \mathrm{~mm}$; two patients in the ONCAB group and four patients in the OPCAB group had atheroma present in both the ascending aorta and the aortic arch; $n=$ number of patients; ONCAB = on-pump coronary artery bypass; $\mathrm{OPCAB}=$ off-pump coronary artery bypass.

TABLE III Patients with grade 1 and grade 2 atheroma of the proximal thoracic aorta and new ischemic brain lesions on DW-MRI

\begin{tabular}{llll}
\hline & $\begin{array}{l}\text { OPCAB group } \\
(n=13)\end{array}$ & $\begin{array}{l}\text { ONCAB group } \\
(n=13)\end{array}$ & P value \\
\hline $\begin{array}{l}\text { New DW-MRI lesions } \\
\text { Present }\end{array}$ & $0(0)$ & $8(61)$ & 0.001 \\
$\begin{array}{l}\text { Absent } \\
\begin{array}{l}\text { Old MRI lesions } \\
\text { Present }\end{array}\end{array}$ & $13(100)$ & $5(39)$ & \\
Absent & $2(15)$ & $3(23)$ & 0.619 \\
\hline Das & $11(85)$ & $10(77)$ & \\
\hline
\end{tabular}

Data presented as number of patients (\%). DW-MRI $=$ diffusionweighted magnetic resonance imaging. $\mathrm{ONCAB}=$ on-pump coronary artery bypass; $\mathrm{OPCAB}=$ off-pump coronary artery bypass.

\section{Aortic atheroma characteristics}

In order to achieve a 1:1 risk-adjusted match with 13 ONCAB patients we performed intraoperative TEE and epiaortic scanning on 30 consecutive patients over $60 \mathrm{yr}$ of age undergoing OPCAB surgery. This screening selected 13 OPCAB patients with comparable (grade 1 and grade 2) atheroma of the proximal thoracic aorta. Based on primary inclusion criteria the remaining 17 patients were excluded from the study (15 patients had grade 0 aorta, one patient had grade 3 atheroma, and one patient required intraoperative conversion to ONCAB surgery).

There was no significant difference with respect to the maximal height of atheroma (the worst lesion) between the two groups; OPCAB, $5.0 \pm 2.0 \mathrm{~mm}$ vs $\mathrm{ONCAB}, 4.8 \pm 1.9$ (data shown as mean $\pm \mathrm{SD}$ ). The location and severity of atheroma were similar between the ONCAB and OPCAB groups (Table II). In the ONCAB group; three patients had atheroma limited to the ascending aorta, eight patients had atheroma restricted to the aortic arch, and two patients had

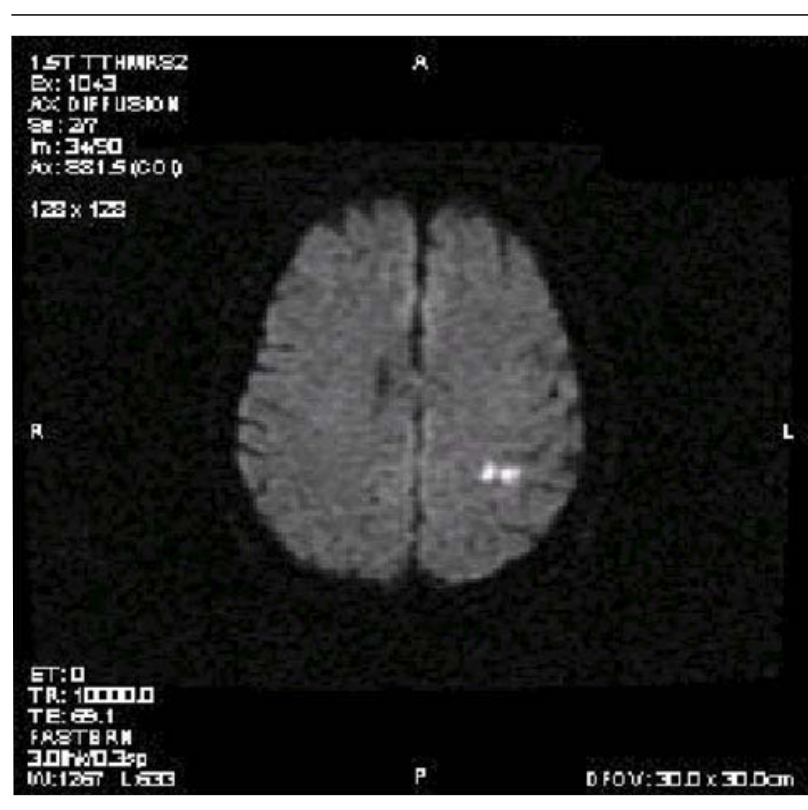

FIGURE 1 Diffusion-weighted magnetic resonance imaging and new ischemic brain lesions after coronary artery bypass graft surgery.

atheroma present in both ascending aorta and aortic arch. In the OPCAB group; two patients had atheroma limited to the ascending aorta, seven patients had atheroma restricted to the aortic arch, and four patients had atheroma present in both ascending aorta and aortic arch.

\section{Magnetic resonance imaging findings}

None of the patients in the OPCAB group had new ischemic brain lesions on DW-MRI. On the contrary, eight of 13 patients in the ONCAB group had new ischemic brain lesions (Table III). Atheroma was restricted to aortic arch in four of these patients. The prevalence of preexisting lacunar infarcts on T2 imaging was similar between the two groups. An example of new DW-MRI lesions is reflected in Figure 1.

\section{Assessment of consciousness}

Confusion was identified in two patients in the OPCAB group and six patients in the ONCAB group. NEECHAM scores were significantly worse in the ONCAB group during the first two postoperative days (Figure 2). None of the patients had any clinically significant metabolic changes that would justify this altered level of consciousness. One patient in the ONCAB group had a clinical stroke with a lesion in the motor cortex of the left hemisphere. 


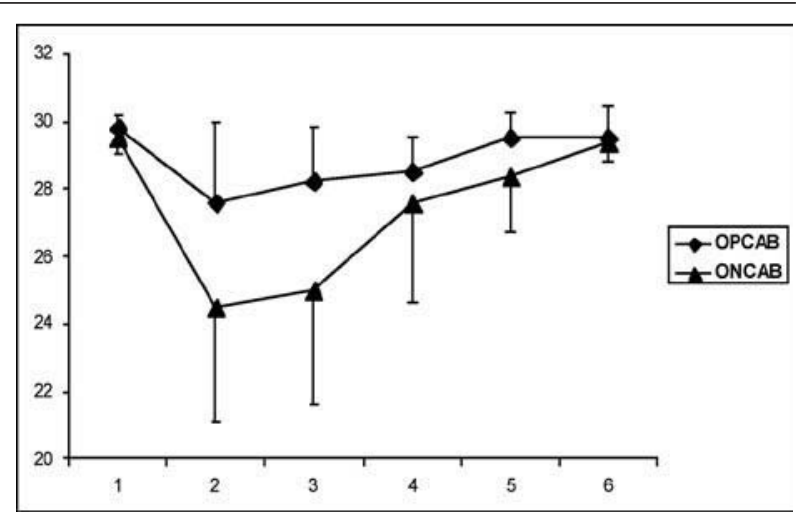

FIGURE 2 Comparison of NEECHAM scores between the off-pump coronary artery bypass (OPCAB) and on-pump coronary artery bypass $(\mathrm{ONCAB})$ groups. $\mathrm{POD}=$ postoperative day.

TABLE IV Postoperative outcomes and complication rates

\begin{tabular}{|c|c|c|c|}
\hline & $\begin{array}{l}\text { OPCAB group } \\
(n=13)\end{array}$ & $\begin{array}{l}\text { ONCAB group } \\
(n=13)\end{array}$ & P value \\
\hline $\begin{array}{l}\text { Postoperative } 24 \mathrm{hr} \\
\text { chest tube loss, } \mathrm{mL}\end{array}$ & $764 \pm 397$ & $648 \pm 309$ & 0.41 \\
\hline $\begin{array}{l}\text { Blood product transfusion } \\
\text { rate, } n(\%)\end{array}$ & $4(31)$ & $3(23)$ & 0.658 \\
\hline Extubation time (hr) & $3.7 \pm 2.1$ & $4.7 \pm 2.4$ & 0.26 \\
\hline Atrial fibrillation, $n(\%)$ & $4(31)$ & $5(38)$ & 0.68 \\
\hline Stroke, $n(\%)$ & $0(0)$ & $1(7.7)$ & $\mathrm{NA}$ \\
\hline $\begin{array}{l}\text { Hospital length } \\
\text { of stay (days) }\end{array}$ & $5.5 \pm 1.6$ & $6.4 \pm 2.0$ & 0.24 \\
\hline
\end{tabular}

\section{Perioperative outcomes}

There were no significant differences with respect to postoperative blood loss and blood product utilization between groups. Times to extubation of the trachea, and hospital length of stay were comparable between the two groups (Table IV).

\section{Discussion}

The results of this study suggest that patients with the proximal thoracic aortic atheroma may have a low risk of DW-MRI new ischemic brain lesions after OPCAB surgery. In contrast, if patients with similar preoperative characteristics and extent of atheromatous disease are exposed to $\mathrm{CPB}$, the prevalence of these brain lesions exceeds $60 \%{ }^{9}$
Although new DW-MRI brain infarcts have been reported to occur in $21-45 \%$ of patients after $C A B$ surgery with $\mathrm{CPB},{ }^{12-16}$ none of these series stratified patients on the basis of aortic atheroma. Interestingly, patient ages were comparable in previous reports, suggesting a possible frequency and distribution of atheroma in the proximal thoracic aorta similar to our cohort of patients. Therefore, had these patients been stratified according to the severity of aortic atheroma, the prevalence of new ischemic brain lesions may have been considerably higher. These findings become important with respect to patient risk stratification based on the aortic atheromatic burden that may reduce the risk of perioperative neurological injury.

Contrary to ONCAB surgery, OPCAB surgery is associated with reduced cerebral embolic load. ${ }^{17-21}$ Nevertheless, a recent meta-analysis of randomized controlled trials (RCTs) by Cheng et al. ${ }^{22}$ failed to show any benefit in neurological and neurocognitive outcomes with $\mathrm{OPCAB}$ surgery. With respect to perioperative stroke, we reached similar conclusions to Cheng et al., ${ }^{22}$ in our meta-analysis of 37 RCTs comparing $\mathrm{ONCAB}$ and $\mathrm{OPCAB}$ treatment modalities. However, the OPCAB technique was associated with significant reduction in stroke in a meta-analysis of 22 risk-adjusted observational studies evaluating patients at high risk for neurological injury. ${ }^{23}$ It was likely that lower stroke rates after OPCAB surgery were secondary to less aortic manipulation and reduced cerebral embolic load in patients with atheromatous aorta. ${ }^{24-26}$ The discrepancies between the RCTs and risk-adjusted observational studies may be attributed to different patient populations being studied, i.e., the RCTs are usually associated with recruitment of low-risk patients whilst the observational studies better reflect patient diversity similar to that of clinical practice.

Similarly to our findings, a small RCT conducted by Baker et al. ${ }^{27}$ found that new DW-MRI lesions were present in three $(33 \%)$ patients in the ONCAB $(n=9)$ group and one $(7.7 \%)$ patient in the OPCAB $(n=13)$ group..$^{27}$ Contrary to our findings, Friday $e t$ al. ${ }^{28}$ reported that new DW-MRI lesions were present in five $(31 \%)$ of 16 patients after OPCAB surgery. Unfortunately, the authors did not report on the extent and severity of aortic atheroma. These reports further emphasize the controversy between ONCAB and $\mathrm{OPCAB}$ treatment strategies with respect to neurological outcomes. Likely resolution to this debate may arrive from an adequately powered RCT including patients at high risk from neurological injury. In order to prevent a possible under-powering of such a study we have lowered the potential frequency of new ischemic brain infarcts in the $\mathrm{ONCAB}$ group from 
$60 \%$ to $45 \%$. As a result, to see a one-third reduction (from $45 \%$ to $30 \%$ ) in new brain infarcts in patients undergoing $\mathrm{OPCAB}$ surgery, with $\alpha=0.05$ and power $1-\beta=0.8$, a group of 175 patients in each arm of the study would be required.

Although our current study is not a randomized trial, we attempted to compare two risk-adjusted (atheroma burden) groups of patients exposed to two treatment modalities. The decision regarding scheduling patients for ONCAB or OPCAB surgery was made by the operating surgeon taking into account patient preferences. It is likely that patients with significant atheromatous disease of the ascending aorta (particularly mobile atheroma) may benefit from OPCAB surgery, and if the surgeon suspects that the patient is at high risk from perioperative stroke, the $\mathrm{OPCAB}$ technique may become the technique of choice. Although this approach clearly introduces bias, the risk factors for perioperative stroke (history of stroke, atrial fibrillation, symptomatic carotid artery disease, 'porcelain aorta', or mobile plaques) were part of the exclusion criteria in this study i.e., minimizing this very bias. Furthermore, patients who were scheduled for $O P C A B$ surgery and were converted to ONCAB intraoperatively were also excluded due to higher morbidity and mortality in this particular subgroup.

The findings of our current study are limited to patients with grade 1 and grade 2 atheroma. The reason for not including patients with normal aorta (grade 0) was based on our previous observation where the lack of new DW-MRI brain lesions was demonstrated in a subgroup of 37 patients with normal aorta. In contrast, eight of 13 patients with grade 1 or grade 2 atheroma had new DW-MRI lesions. Moreover, half of these patients had normal ascending aorta and atheroma restricted to the aortic arch. ${ }^{9}$ Consequently, the same weight was given to the location of atheroma in the ascending aorta or the aortic arch in both study groups.

The current study design did not merit formal neuropsychological assessment of cognitive function. However, our results support the findings of a recent meta-analysis of risk adjusted observational studies ${ }^{23}$ favouring the $\mathrm{OPCAB}$ technique for stroke reduction. To assess patient consciousness status we utilized the NEECHAM confusion scale which has been shown to reflect clinical impact of cerebral embolic load and new DW-MRI lesions after ONCAB surgery. ${ }^{9}$ Current DW-MRI technology permits detection of the embolic ischemic lesions $\geq 3 \mathrm{~mm}$ with unprecedented accuracy. The reported sensitivity and specificity of DW-MRI exceeds $90 \%$, specifically, for acute subcortical infarction it is $94.9 \%$ and $94.1 \%$ respectively. ${ }^{29}$
Diffusion-weighted magnetic resonance imaging is rapidly becoming a gold standard on which both early diagnosis and early treatment strategies of stroke are currently predicted. ${ }^{30}$

In conclusion, our study demonstrates that patients with aortic atheroma $>2 \mathrm{~mm}$ may have a low risk of new DW-MRI ischemic brain lesions after OPCAB surgery when compared to ONCAB surgery. Patient stratification based on the aortic atheromatic burden should be addressed in future trials designed to tailor treatment strategies to improve short- and long-term outcomes of patients with coronary artery disease.

\section{References}

1 Selnes OA, Goldsborough MA, Borowicz LM, McKhann $G M$. Neurobehavioural sequelae of cardiopulmonary bypass. Lancet 1999; 353: 1601-6.

2 Newman MF, Kirchner JL, Phillips-Bute B, et al.; Neurological Outcome Research Group; Cardiothoracic Anesthesiology Research Endeavors Investigators. Longitudinal assessment of neurocognitive function after coronary-artery bypass surgery. $\mathrm{N}$ Engl J Med 2001; 344: 395-402.

3 Borger MA, Ivanov J, Weisel RD, Rao V, Peniston CM. Stroke during coronary bypass surgery: principal role of cerebral macroemboli. Eur J Cardiothorac Surg 2001; 19: 627-32.

4 Davila-Roman VG, Barzilai B, Wareing TH, Murphy $S F$, Schechtman KB, Kouchoukos NT. Atherosclerosis of the ascending aorta: prevalence and role as an independent predictor of cerebrovascular events in cardiac patients. Stroke 1994; 25: 2010-6.

5 Mizuno T, Toyama M, Tabuchi N, et al. Thickened intima of the aortic arch is a risk factor for stroke with coronary artery bypass grafting. Ann Thorac Surg 2000; 70: 1565-70.

6 van der Linden J, Hadjinikolaou L, Bergman P, Lindblom $D$. Postoperative stroke in cardiac surgery is related to the location and extent of atherosclerotic disease in the ascending aorta. J Am Coll Cardiol 2001; 38: 131-5.

7 Katz ES, Tunick PA, Rusinek H, Ribakove G, Spencer FC, Kronzon I. Protruding aortic atheromas predict stroke in elderly patients undergoing cardiopulmonary bypass: experience with intraoperative transesophageal echocardiography. J Am Coll Cardiol 1992; 20: 70-7.

8 Tunick PA, Kronzon I. Atheromas of the thoracic aorta: clinical and therapeutic update. J Am Coll Cardiol 2000; 35: 545-54.

9 Djaiani G, Fedorko L, Borger M, et al. Mild to moderate atheromatous disease of the thoracic aorta and new ischemic brain lesions after conventional coronary artery bypass graft surgery. Stroke 2004; 35: e356-8. 
10 Ura M, Sakata R, Nakayama Y, Goto T. Ultrasonographic demonstration of manipulationrelated aortic injuries after cardiac surgery. J Am Coll Cardiol 2000; 35: 1303-10.

11 Neelon VJ, Champagne MT, Carlson JR, Funk SG. The NEECHAM confusion scale: construction, validation, and clinical testing. Nurs Res 1996; 45: 324-30.

12 Toner I, Peden CJ, Hamid SK, Newman S, Taylor KM, Smith PL. Magnetic resonance imaging and neuropsychological changes after coronary artery bypass graft surgery: preliminary findings. J Neurosurg Anesthesiol 1994; 6: 163-9.

13 Vanninen R, Aikia M, Kononen M, et al. Subclinical cerebral complications after coronary artery bypass grafting. Prospective analysis with magnetic resonance imaging, quantitative electroencephalography, and neuropsychological assessment. Arch Neurol 1998; 55: 618-27.

14 Bendszus $M$, Reents W, Franke D, et al. Brain damage after coronary artery bypass grafting. Arch Neurol 2002; 59: 1090-5.

15 Restrepo L, Wityk RJ, Grega MA, et al. Diffusion- and perfusion-weighted magnetic resonance imaging of the brain before and after coronary artery bypass grafting surgery. Stroke 2002; 33: 2909-15.

16 Knipp SC, Matatko N, Wilhelm H, et al. Evaluation of brain injury after coronary artery bypass grafting. A prospective study using neuropsychological assessment and diffusion-weighted magnetic resonance imaging. Eur J Cardiothorac Surg 2004; 25: 791-800.

17 Abu-Omar Y, Cifelli A, Matthews PM, Taggart DP. The role of microembolisation in cerebral injury as defined by functional magnetic resonance imaging. Eur J Cardiothorac Surg 2004; 26: 586-91.

18 Bowles BJ, Lee JD, Dang CR, et al. Coronary artery bypass performed without the use of cardiopulmonary bypass is associated with reduced cerebral microemboli and improved clinical results. Chest 2001; 119: 25-30.

19 Lee JD, Lee SJ, Tsushima WT, et al. Benefits of offpump bypass on neurologic and clinical morbidity: a prospective randomized trial. Ann Thorac Surg 2003; 76: $18-25$.

20 Lund C, Hol PK, Lundblad R, et al. Comparison of cerebral embolization during off-pump and on-pump coronary artery bypass surgery. Ann Thorac Surg 2003; 76: 765-70.

21 Watters MP, Cohen AM, Monk CR, Angelini GD, Ryder $I G$. Reduced cerebral embolic signals in beating heart coronary surgery detected by transcranial Doppler ultrasound. Br J Anaesth 2000; 84: 629-31.

22 Cheng DC, Bainbridge D, Martin JE, Novick RJ; Evidence-Based Perioperative Clinical Outcomes Research Group. Does off-pump coronary artery bypass reduce mortality, morbidity, and resource utilization when compared with conventional coronary artery bypass? A meta-analysis of randomized trials. Anesthesiology 2005; 102: 188-203.

23 Wijeysundera DN, Beattie WS, Djaiani GN, et al. Offpump coronary artery surgery for reducing mortality and morbidity. Meta-analysis of randomized and observational studies. J Am Coll Cardiol 2005; 46: 872-82.

24 Grossi EA, Bizekis CS, Sharony R, et al. Routine intraoperative transesophageal echocardiography identifies patients with atheromatous aortas: impact on «offpump» coronary artery bypass and perioperative stroke. J Am Soc Echocardiogr 2003; 16: 751-5.

25 Kapetanakis EI, Stamou SC, Dullum MK, et al. The impact of aortic manipulation on neurologic outcomes after coronary artery bypass surgery: a risk-adjusted study. Ann Thorac Surg 2004; 78: 1564-71.

26 Lev-Ran O, Braunstein R, Sharony R, et al. No-touch aorta off-pump coronary surgery: the effect on stroke. J Thorac Cardiovasc Surg 2005; 129: 307-13.

27 Baker MD, Moody DM, Field AS, Yen YF, Hammon $J W$, Stump DA. Advanced magnetic resonance imaging techniques of perfusion and diffusion in evaluation of postsurgical brain injury: preliminary results in coronary artery surgery on and off cardiopulmonary bypass. Ann Thorac Surg 2002; 73: S367.

28 Friday G, Sutter F, Curtin A, et al. Brain magnetic resonance imaging abnormalities following off-pump cardiac surgery. Heart Surg Forum 2005; 8: E105-9.

29 Singer MB, Chong J, Lu D, Schonewille WJ, Tubrim S, Atlas $S W$. Diffusion-weighted MRI in acute subcortical infarction. Stroke 1998; 29: 133-6.

30 Guadagno JV, Calautti C, Baron JC. Progress in imaging stroke: emerging clinical applications. Br Med Bull 2003; 65: 145-57. 